\title{
Farklı Bakış Açılarıyla Sürdürülebilir Mimarlık-Estetik İlişkisinin Kurulması
}

\author{
Demet YILMAZ $^{1 *}$, Kader KESKIN ${ }^{2}$
}

Öz

Son yıllarda artan çevre sorunları beraberinde yaşanan sorunlara karşı çözümler aramayı ve çevreye duyarlı yaklaşım anlayışını getirmiştir. Bu doğrultuda çevreye karşı zararı yadsınamayacak kadar büyük olan yapı sektörü de çevreye saygılı, yenilenebilir enerji kaynaklarının kullanımına öncelik veren, kullanılan enerji miktarını en aza indirgemeyi amaçlayan sürdürülebilir mimarlık anlayışı ile tanışmıştır. Çevreye saygılı ve akılcı yaklaşımlarla gelecek nesillerin de yaşamını düşünen sürdürülebilir mimarlık kavramı, doğal çevrenin yanı sıra sosyal ve kültürel değerlerin korunması, çevre kalitesinin artırılması, insan sağlığı ve konforu gibi farklı kavramlar üzerinde de sorumluluk taşımaktadır.

Bu düşüncenin başladığı günden bugüne sayıları artan her bir sürdürülebilir yapı, aynı zamanda yapılı çevrenin bir parçası olarak direk amacı olsun ya da olmasın çevrenin estetik değerine etkisi vardır. Bu bağlamda çalışmada sürdürülebilir mimarlık ile estetik ilişkisi, örnekler üzerinde yapılan analizler, kuramcıların, mimarların görüşleri ve tasarım eğitimi almış bir grubun gözünden değerlendirilmiştir. Çalışma hangi tür sürdürülebilir yapıların daha estetik bulunduğu noktasında tasarımcıya bakış açısı sunması açısından özgün olmaktadır.

Anahtar Kelimeler: Sürdürülebilirlik, Mimarlık, Estetik, Form, Cephe

\section{Establishing Sustainable Architecture - Aesthetic Relationship with Different Perspectives}

\begin{abstract}
In recent years, increasing environmental problems have led to the search for solutions to the problems experienced and the understanding of environmentally sensitive approach. In this respect, the construction sector, which is too large to deny damages to the environment, is introduced to the concept of sustainable architecture that respects the environment, prioritizes the use of renewable energy resources and aims to minimize the amount of energy used. The concept of sustainable architecture, which considers the lives of future generations with respectful and rational approaches to the environment, bears responsibility on different concepts such as protection of social and cultural values, increasing environmental quality, human health and comfort besides natural environment.
\end{abstract}

Every sustainable structure, which has been increasing since the beginning of this thought, also has an impact on the aesthetic value of the environment, whether or not it has a direct purpose as part of the built environment. In this context, the relationship between sustainable architecture and aesthetics, the analysis of the examples, theorists, architects' views were evaluated from the perspective of a group who

\footnotetext{
${ }^{1}$ Karadeniz Teknik Üniversitesi, Mimarlık Fakültesi, Mimarlık Bölümü, Trabzon, Türkiye

${ }^{2}$ Ondokuzmayıs Üniversitesi, Mimarlık Fakültesi, Mimarlık Bölümü, Samsun, Türkiye,

* Illgili yazar/Corresponding author: yilmazdemett@ktu.edu.tr 
received design education. The study is unique in that it provides the designer with a perspective on which sustainable structures are more aesthetic.

Keywords: Sustainable, Architecture, Aesthetics, Form, Facade

\section{GiRiş}

Yapı endüstrisindeki bilinçsiz yapım, kullanım, yıkım aktiviteleri sonucunda oluşan katı, sıvı atıklar ve gaz emisyonları çevreye zarar vermekte; biyolojik çeşitliliğin azalması, tarım alanlarının kaybı, hava, su ve toprak kirliliği, doğal yeşil alanların yok olması ve küresel ısınma gibi pek çok alanda olumsuz etkiye neden olmaktadır. Yapılardan kaynaklanan bu çevresel sorunlara kalıcı çözümler üretebilmek amacıyla 'sürdürülebilir mimarlık' kavramı ortaya çıkmıştır.

Temelde sürdürülebilir mimarlık, ekolojik dengeye duyarlı, bölgenin iklim verilerini dikkate alan, doğal ve yenilenebilir enerji kaynaklarını kullanan, geri dönüşümlü malzemelerin kullanımına öncelik veren doğa dostu, çevreye duyarlı mimarlık yaklaşımı olarak tanımlanırken (Yeang, 2006, s.23; Keskin, 2014, s.8) diğer taraftan bu yaklaşım, insan sağlığı ve konforunun yanı sıra yapılı çevrenin kalitesini artırmayı da hedeflemektedir (Kim ve Rigdon, 1998, s.7)

Mimari bir formun pragmatik, sosyolojik ve estetik olarak birden çok etkisi bulunmaktadır (Baird, 2002, s.76). Yapılar tekil yapılar olmasına rağmen kentsel ölçekte bir bütünün parçalarıdır. Bu bağlamda bakıldığında yapılar, kentlerin yaşam kalitesinde ve kent kimliğinde önemli bir faktör olarak karşımıza çıkmaktadır (Lee, 2011, s.29). Garshasbi (2013), yapıların çevreyle olan bağlantısının, nasıl göründüğünün, uyumunun, estetik yaklaşımının insanları etkileyebildiğini söylemektedir (Sendi, 2014, s.2).

Çalışma, günümüzde yapılı çevre içinde sayıları gittikçe artan sürdürülebilir mimari ürünlerin ekolojik denge ve insan konforunu sağlama hedeflerinin yanında çevrenin estetik kalitesine etkisinin tasarım hedefi olup olmadığı veya olması gerekip gerekmediği konusunda kuramcıların, mimarların değerlendirmeleri, bu ilişkinin yapı örnekleri üzerinde bina dış yüzeyinde nereye yansıdığı, kullanılan malzemenin ne olduğu, ne amaçla kullanıldığı ve bir değişim geçirip geçirmediği gibi sorulara cevap aramaktadır. Ayrıca çalışmanın sonunda bu örnekler, mimarlık eğitimi almaya devam eden son sınıf öğrencilerine estetik açıdan değerlendirtilmiştir. Böylece çalışmada sürdürülebilir mimarlık-estetik ilişkisi farklı bakış açılarıyla ortaya koyulmaya çalışılmıştır.

\section{SÜRDÜRÜLEBILIR MIMARLIK ve ESTETIKK KAVRAMI}

Farklı araştırmacılara göre 'sürdürülebilirlik' genel olarak; 'kaynakları ve doğal döngüleri tüketmeyen ve onlara zarar vermeyen metod, sistem ve malzemelerin kullanılması anlamına gelmektedir (Rosenbaum, 1993, s.42). Ayrıca yaşam kalitesini düşürmeden, düşünce tarzında değişiklik gerektiren bir kavram ortaya koymaktadır. Bu değişikliğin özü ise tüketim toplumu olmaktan sıyrılıp, evrensel açıdan dayanışma içinde olan, çevresel yönetim, toplumsal sorumluluklar ve ekonomik çözümler hedeflemeye dayanmaktadır (Jeffery, 2006, s.11).

Sev (2009)'e göre sürdürülebilir mimarlık, içinde bulunduğu koşullarda ve varlığının her döneminde, gelecek nesilleri de dikkate alarak, yenilenebilir enerji kaynaklarının kullanımına öncelik veren, çevreye duyarlı, enerjiyi, suyu, malzemeyi ve bulunduğu 
alanı etkin şekilde kullanan, insanların sağlık ve konforunu koruyan yapılar ortaya koyma faaliyetlerinin tümüdür. Başka bir deyişle insanların mekan gereksinmelerini, doğal sistemlerin varlığını ve geleceğini tehlikeye sokmadan yerine getirmeyi hedefleyen mimari tasarım ve uygulamalardır (Sev, 2009, s.31).

Sürdürülebilir mimarlıkta yapıların çevreye uygunluğu ne kadar fazlaysa, tasarım da o kadar sürdürülebilir demektir. Sürdürülebilirlik, somut veya soyut malzemelerin bir ideal çerçevesinde bir araya gelmesi için bir ölçüttür (Bauer vd., 2007, s.25).

Kim ve Rigdon (1998), sürdürülebilir mimarlık ilkelerini kaynakların etkin kullanımı, yaşam döngüsü tasarımı, insan yaşam kalitesinin artırılması ve estetik olarak üç grupta toplamaktadır. Kaynakların etkin kullanımını, yapı malzemelerinin üretimi ile başlayan ve bina yaşam döngüsünce devam eden, yenilenemeyen enerji kullanımını azaltan önemli bir ilke olarak tanımlarken yaşam döngüsü tasarımını; tasarım, inşaat, operasyon ile bakım ve yıkım evreleri olarak ele almaktadır. İnsan yaşam kalitesinin artırılmasının ise insan sağlığı ve konforunu korumanın yanı sıra, insanın yaşam standardını, kültürel, sosyal ve fiziksel çevre kalitesini arttırmayı ve geliştirmeyi hedeflemek olduğunu belirtmektedir (Kim ve Rigdon, 1998, s.8)

İnsan fiziksel çevresini oluştururken onu güzelleştirmek ister. İnsanın çevresini ve elemanlarını güzelleştirme arzusu ile oluşan 'estetik' olgu, mimari ürünün biçimlendirilmesi ve değerlendirilmesinde önemli bir yere sahiptir. Estetik açıdan insanları memnun eden bu doygunluk, mimari ürünün değerlendirilmesinde temel ölçüt olarak kabul edilmektedir (Kuban, 2005, s.56).

Vitruvius'a göre (2005) bir mimari ürünün başarılı olabilmesi estetik kavramı için önemli kriterlerden biridir. İyi bir mimari ürün kullanışlı, sağlam ve estetik olmalıdır (Vitruvius, 2005, s.12). Kuban (2015)'a göre ise bir yapının güzel olması dış biçimi, iç sınırları, boşlukları, rengi, yüzeylerinin dokusu ve ölçüleri, ışı̆̆ı ve gölgesiyle de hoşa gitmesi ve insan beğenisini tatmin etmesi anlamına gelmektedir. Çok kere bu beğeni, sadece saf estetik hislerle değil, toplumsal sembolik değerlerle belirmektedir. Bu bakımdan biçimlendirme öznel, salt faydayı aşan nitelikleri kapsamakta ve daha geniş bir fayda, daha geniş bir intiyaç, daha genel bir fonksiyon tanımlamayı gerektirmektedir. Bu geniş kapsamlı güzellik isteğini de içeren ihtiyaç ancak toplum kültürünün tümünün içinde bir anlam taşımaktadır (Kuban, 2005, s.56).

Tarih boyunca estetik kaygılardan uzak tutulmayan mimarlık, farklı dönemlerde farklı nitelik taşıyan ürünler vermiştir. Estetik kaygı, mimari ürünün iç mekanında, dış mekanında, yapı bütününde karşımıza çıkmaktadır. Estetik arayış için farklı kriterler, kurallar, kılavuzlar ve ilkeler oluşturulmuştur.

\section{ARAŞTIRMA}

Yapılı çevre içerisinde gün geçtikçe sayısı artan sürdürülebilir yapılar, sürdürülebilirlik, teknolojik ve mimari tasarım ilkeleri doğrultusunda karmaşık bir ilişkiler bütünü içerisinde kendine yer bulmaktadır. Dolayısıyla sürdürülebilir yapılar sadece sürdürülebilirlik özellikleri ile değil, çevreye kattığı estetik özellikleriyle de ele alınmalıdır.

Çalışmanın ilk bölümünde farklı görüşler ve kuramlar üzerinden sürdürülebilir mimarlıkla estetik ilişkisi tartışımıştır. Sürdürülebilir yapıların estetik kaygı taşıyıp taşımadıkları, taşıması gerekip gerekmediği, tasarım hedeflerinden biri olup olmadığı gibi sorulara cevap aranmaktadır. İkinci bölümünde sürdürülebilir yapı örnekleri 
öncelikle yapı strüktüründeki yerine göre gruplanıp kronolojik bir sırada verilerek örnekler üzerinden sürdürülebilir yapıların geçirdiği değişim ortaya konmaya çalışılmıştır. Sürdürülebilir mimari anlayışının ve uygulamaların teknolojinin gelişimiyle birlikte 2000'li yıllarda kırıma noktasına ulaştığı görülmektedir. Bu sebeple araştırma kapsamında seçilen örnekler kırılma noktasına bağlı olarak estetik gelişiminin daha iyi analiz edilebilmesi için sürdürülebilir tasarım anlayışının benimsenmeye başlandığı 1970'lerden - 2000' e ve 2000 ve sonrası olmak üzere iki farklı çizelgede yapım tarihine bağlı olarak gruplandırılmıştır. Ayrıca örneklemede sürdürülebilir tasarımın temel bileşeni olan özellikle yapı kabuğunu oluşturan cephe, çatı ve kütle ölçekleri incelenmiştir. Böylece sürdürülebilirlik anlayışının yapı bütünündeki etkisi de ortaya konmaya çalışılmıştır.

Son bölümde ise seçilen bu örnekler estetik açıdan değerlendirilmiştir. Mimarlık bölümü son sınıfa devam eden 100 öğrenciye yapıyı farklı açılardan gösteren yapının uzak ve yakın fotoğraflarından oluşturulmuş bir power point sunu gösterilmiş, her bir örneği estetik açıdan 1 en az 7 en fazla olmak üzere değerlendirmeleri istenmiştir. Ayrıca yapıyı estetik buldukları bina bölümünü de (çatı/cephe/kütle) belirtmeleri istenmiştir.

\subsection{Bulgular ve değerlendirmeler}

Sürdürülebilirlik mimarlık- estetik ilişkisi kuramcılar ve mimarların görüşleri, örnekler üzerinden yapılan değerlendirmeler ve anket verilerine göre üç bölümde ele alınmıştır.

\section{Kuramcılar ve mimarların görüşleri üzerinden sürdürülebilir mimarlık-estetik ilişkisi;}

Doğaya hükmeden değil onunla uyumlu yaşama düşüncesi gün geçtikçe yapılı çevre içerisinde yaygınlaşmaya başlamıştır. Bu kapsamda, dünyada sayısı artan yaşanabilir çevreler elde edilmesi sürecinde sürdürülebilir yapılar; sürdürülebilir, bilimsel, teknolojik ve mimari tasarım ilkeleri kapsamında biçimlenmektedir. Yerin fiziksel çevre özelliklerine bağlı olarak hareket eden sürdürülebilir mimarlık, fiziksel çevreye ek olarak teknolojik gelişmelerin beraberinde getirdiği eko - teknolojik ürünlerle birlikte farklı çözümlerle karşımıza çıkmaktadır. Bu sebeple sürdürülebilir mimari yapılar birden fazla veriyi kullanma sebebiyle karmaşık bir ilişkiler bütünü içerisinde olabilmektedir. Bu karmaşa Lee ve Holzheu'nun estetik böyle bir karmaşık ağ içerisinde yapılı çevre için sadece basit bir aracı ve uygun görevi yerine getirme midir? sorusunu gündeme getirmiştir (Lee ve Holzheu 2011, s.120).

- Peter Einsenman (2009) Columbia Üniversitesi'ndeki dersinde Us Green Building Konseyinin bina değerlendirme sistemi ile ilgili konuşurken 'Yeşil ve sürdürülebilirliğin mimarlıkla bir ilgisi yoktur... Hayatımda gördüğüm en çirkin yapılardan bazıları sürdürülebilir mimarlık tarafından yapılmıştır... altın, gümüş ve platin Leedserifikalı binalardır... mimari olarak berbatlar... moral bozucular' ifadesini kullanmıştır (Jauslin, 2011, s.109).

- Mimar Wolf Prix (2009) Münih Opera Festivali için ders açılışında 'Sürdürülebilirlik anlamlılığı yanıltır, bu yüzden sürdürülebilirlik teriminden estetik üretmek mümkün değildir. Modern mimari olarak sürdürülebilirliğin estetik yaşamı yoktur.' açıklamasını yapmıştır (Jauslin, 2011, s.110).

- Peter Buchanan, sürdürülebilir mimarlığın estetiği diye bir şey olmadığını ve bunun yerine bina formu ve cephesi arasında fark edilmeyen bir bağ olduğunu ve sürdürülebilirliğin bu ince çizgi üzerinde var olduğunu savunmaktadır. Ayrıca mimarlık okullarının özellikle sürdürülebilir estetiğe çok daha fazla odaklandığını; bireysel yaratıcılığın sürdürülebilirliğe katıımının olumsuz etkisi 
olabileceğini belirtmiştir. Elde edilen binaların estetik fakat sürdürülebilirlik anlamında eksik olabileceğini vurgulamaktadır (Frampton, 2012, s.98).

- Rostvik (2011)'e göre sürdürülebilir mimarlık bugün biçim verme, tasarım ve mühendislik gibi mevcut tüm potansiyelleri kontrol edemez. Binaları çevreleri ile uyumlu hale getirmek amacıyla onları sürdürülebilir yapan malzeme ve ürünleri gizlemek için gösterilen çaba estetik uygulamaların bir biçimi değildir (Rostvik, 2011, s.171).

- Alter (2009), sürdürülebilir binaları iğrenç karbon verici binalar olarak betimlemektedir. Tasarımcıların kendilerini LEED' in çizdiği kılavuza göre uyarladığını ve tasarımı unuttukları yönünde eleştiride bulunmuştur (URL-1). ${ }^{3}$

- Hosey (2012) sürdürülebilir yapıları çirkin bulmaktadır. Ancak sürdürülebilirlikteki gerçekliğin çekicilik olmadığını ve bu nedenle sürdürülebilir yapılarda estetiğin aranmayabileceğini de eklemektedir. Hosey, bu durumun zamanla değişeceğini, eko tasarımda çarpıcı örnekler görüneceğini ve görülmesi gerektiğini belirtmektedir (Hosey, 2012, s.2).

- Betsky (2010) sürdürülebilir mimarlığın büyük bir gerçeklik peşinde olduğunu iddia etmiş, üretimini haklı bulduğunu belirtmiştir. Ancak binalarını çirkin bulduğunu belirten düşünür oluşturulan mekanların ve formların ne kullanıcılar için ne de yapılı çevre için iyi olmadığını vurgulamıştır (Hosey, 2012, s.3).

- Kupatadze (2014) sürdürülebilir ürünler tasarlamanın gerekliliğine bağlı olan mimarların tasarımlarında estetik niteliklerine daha az özen gösterdiklerini ve yaratıcılık özgürlüklerini yitirdiğini belirtmektedir. Düşünür, yaratıcılığın çevre bilincine odaklanarak kısıtlandığını ve bu nedenle sürdürülebilir mimarlığın mimarların yaratıcılığını sınırlandırdığını aktarmaktadır. Gün ışı̆̆ından yararlanma ya da gölgelemeyi sağlama, ısıtma, soğutma gibi enerji etkinliğinde önemli olan kriterler, planlamada tasarımı kısıtlamakta; tasarımcılar bu sürdürülebilir özellikleri düşünürken estetik açıdan güzel olmayan teknik binalar üretmektedir: 'Kesinlikle sürdürülebilir özellikler mimarları sınırlar içinde tutuyor. Ancak her mimar yaratıcı olabilir ve hem estetik açıdan hoş hem de çevreyi rahatlatan formu geliştirebilir. Tek zorluk kutunun dışında düşünmektir' (Kupatadze, 2014, s.561).

- Finocchiaro ve Hestnes, (2011), sürdürülebilir tasarımın estetiğinin gelişmekte olan bir süreç içerisinde olduğunu ve bu estetiğin sıkı sıkıya yeni mimari bileşenlerin, malzemelerin ve tekniklerin gelişimi ile bağlantılı olduğunu düşünmektedir (Finocchiaro ve Hestnes, 2011, s.259).

- Ghani (2012)' e göre sürdürülebilir tasarım, estetik, çevresellik, sosyal, politik ve dürüstlük değerlerin kombinasyonunu kapsamaktadır. Strüktür/malzeme ve estetik tasarımın etkili parametreleridir. İyi bir yaşam alanı ve tasarım için bunlar tasarıma entegre edilmelidir. Ghani, elektrik, makine ve strüktürel mühendislikle yakından ilgili olan sürdürülebilir tasarımın bunlara ek olarak estetikle doğrudan bağlantılı olan oran, ölçek, doku, gölge ve ışıkla da ilgili olduğunu ve sürdürülebilir mimari yapılarda estetiğin de düşünülmesi gerektiğini vurgulamaktadır (Ghani, 2012, s.22).

- Brekke (2014) sürdürülebilir mimarlığın yüksek teknolojili bina, güneş panelleri, yeşil çatılar, düşey bahçeler, rüzgar türbinleri gibi gösterişli binalar olduğunu belirtmiş ve artık sürdürülebilir mimarlığın estetiği üzerinde de konuşulması gerektiğini eklemiştir. Brekke'ye göre sürdürülebilirlik yaratıcılığa ve güzel binalara intiyaç duymaktadır. ${ }^{4}$

\footnotetext{
${ }^{3}$ https://www.treehugger.com/sustainable-product-design/why-is-so-much-green-architecture-so-ugly.html (erişim tarihi 07.03.2019, 17:50)

${ }^{4}$ https://issuu.com/benedictebrekke/docs/aesthetics and sustainable architec (erişim tarihi 09.03.2019, 14:30)
} 
- Berleant (2016) psikoloji, felsefe, politika, edebiyat gibi alanların yanında son zamanlarda estetik arayışın da sürdürülebilirlik için önemli bir paradigma olmaya başladığını, sürdürülebilirlikte estetiğin geliştirilmesi konusunda çalışmaların olduğunu aktarmaktadır. Bu estetik değerin geliştirilmesinde etik değerler ve estetik değerlerin tanınması gerektiğini düşünen kuramcı, bu değerlerin hiç birinin birbirinden önde olmadığını, bu değerlerin karşılıklı olarak birbirini tamamlayıcısı olarak dengede olması gerektiğini vurgulamaktadır (Berleant, 2016, s.130).

- Udomiaye ve arkadaşları (2018) günümüz mimari pratiğininin çevre teknolojiyi dengelemek, uyumlaştırmak ve estetik içeriği bulmak için bir mücadele içerisinde olduğunu vurgulamaktadır. Düşünürlere göre sürdürülebilir bir bina tasarlanırken binalarda konsept, estetik, ekonomik, sosyal ve ekolojik kriterler düşünülmelidir (Udomiaye vd.,2018 s.15).

- Wheeler (2017), mimarlığın ve inşaat alanının gelecekteki ekolojik dünyaları kurma zorunluluğundan bahsetmekte, sürdürülebilir mimarlık ve estetik ilişkisini sorgularken dış etkenlerin yalnızca sürdürülebilir mimarlığa yapılan eleştirilere hizmet etmemesi gerektiğini, estetik hissini yeniden değerlendirerek sürdürülebilir mimarlık söylemini zenginleştirmesi gerektiğini eklemektedir (Wheeler, 2017, s.9).

- Christiaens (2013), sürdürülebilirliğin gereklilikten dolayı uygulamaya koyulduğunu belirterek Koolhaas, Eisenman ve Prix gibi mimarların neden hala sürdürülebilirliği güzel bulmadıklarını açıklaması gerektiğini savunmuştur (Christiaens, 2013, s.8).

- Alman mimar Heringer (2011), sürdürülebilirliği ve güzelliği birbirinin eş anlamlısı olarak değerlendirmiştir. Ona göre bir binanın tasarımı, strüktürü, tekniği, malzemesi, bulunduğu yeri, çevresi, kullanıcısı ve sosyal kültürel bağlamının uyum içerisinde olması sürdürülebilirliği güzel kılmaktadır. ${ }^{5}$

- Guzowski (2008) güneş ve rüzgardan elde edilen pasif enerji kazançlarının teknolojik sistemler ve ekolojik mühendislik toplamından daha fazla olduğunu, bu nedenle binanın hem sanatı hem de bilimi mimarlıkta güzel ve estetik olarak somutlaştığını belirtmiştir. ${ }^{6}$

- Yeang (2002) ekolojik yapıların pahalı olduğunu, estetik olmadığını ve bazı çevre bilimcilerin ekolojik kalitenin estetik olarak çelişkili görünme eğiliminde olduklarını ifade etmektedir. Yeang'a göre eko-teknolojik olarak donatılan veya ekolojik teçhizatlarla doldurulan binalar, görünüşte mekanik olma eğilimindedir ancak doğal kurguyu ve döngüyü kavramak ve ona uyumlu hizmeti üretmek, beraberinde evrensel yeni estetiği getirecektir. Yeang, aşırı teknik gibi görülen enerji gerekçesinin, giderek mimarinin kendisi olacağını, insanları estetik değerlerden uzaklaştırmayacağını, ayağı yere basan enerji teknolojisinin zamanla çok daha kolaylıkla mimari çözümlerde yerini alacağını ve estetik değerlere önemli katkılarda bulunacağını düşünmektedir (Yücel, 2011, s.44).

- Zhe ve arkadaşları (2011) ise sürdürülebilir mimariyi geleceğin mimarlık anlayışında kaçınılmaz bir moda olarak tanımlamıştır (Zhe vd.,2011, s.164).

- Jencks (2002) 20. yy'ın sonlarında etkili olan ve 21. yy'da da etkili olacak olan çevreye duyarlı binaların, arazi yapısı, topolojik yüzey, yeni doğa metaforları ve karmaşıkığıyla ilgili başa çıkma yöntemlerinin mimarlığın yeni paradigmasını ve yeni estetiğini oluşturduğunu belirtmiştir (Wahba, 2010, s.462).

\footnotetext{
${ }^{5}$ https://docplayer.nl/19528613-21-05-28-08-2011-architecture-museum-la-loge-kluisstraat-86-1050-brussel.html (erişim tarihi 11.03.2019, 11:25)

https://arch.design.umn.edu/directory/guzowskim/documents/AIACOTEsolar.pdf （erişim tarihi 10.03.2019, 15:20)
} 
Tablo 1. Sürdürülebilir mimarlık- estetik ilişkisi üzerine görüşler

Sürdürülebilir Mimarlık- Estetik İlişkisi Üzerine Görüşler

Peter Einsenman ...çirkin yapılar...

Aaron Betsky ... çirkin yapılar...

Kupatadze ...güzel olmayan teknik binalar

Wolf Prix ... estetik yaşamı yoktur...

Harad N. Røstvik ...gizlemek estetik yaratmak olamaz...

Peter Buchanan ... estetiği yoktur...

Lance Hosey ...çirkindir ama gelecekte sürdürülebilirliğin estetikle ilişkisi kurulacak veya kurulmalı...
Fatima Ghani...sürdürülebilir tasarım estetikle doğrudan bağlantılı ...tasarımda bu ilişki kurulmalı...

Anna Heringer... sürdürülebilirlik ve güzellik eş anlamlıdır...

Mary Guzowski ... hem sanatın hem de bilimin mimarlıkta güzel ve estetik olarak somutlaşması...

David Jauslin ...gerekliliktir...bu

sürdürülebilirliği güzel kılar...

Udoamiye ... sürdürülebilir bir bina

tasarımında estetik de bir kriter...

Liv Benedicte Brekke ...sürdürülebilirliğin yaratıcılığa ve güzel binalara ihtiyacı var...

Wheeler ... estetik hissini yeniden değerlendirerek sürdürülebilir mimarlık söylemini zenginleştirmeli...

Berleant...estetik sürdürülebilirlik için önemli bir paradigma olmaya başladı...

Ken Yeang... ilerde gelişmelerle evrensel yeni estetiği getirecek...

Luca Finocchiaro ve Anne Grete Hestnes .. sürdürülebilirlikte estetik yeni gelişmekte...

Jenks ...yeni bir estetik oluşturuyor...

Özetle Einsenman, Betsky, Alter, Kupatadze, Prix, Røstvik, Buchanan ve Hosey sürdürlebilir yapıları çirkin bulmuştur. Hosey, Ghani, Brekke ve Hosey gelecekte bu ilişkininin kurulacağını, Buchanan ise bu ilişki kurulursa yapıların sürdürülebilirlik açısından olumsuz etkileneceğini belirtmiştir. Alter ve Kupatadze sürdürülebilirlik kriterlerinin yaratıcılığı kısıtladığını vurgulamıştır. Jauslin, Heringer ve Guzowski gereklilikten ortaya çıkan sürdürülebilirlikte estetik aranmaması gerektiğini ve zaten estetik olduğunu düşünmektedir. Finocchiaro, Hestnes, Ken Yeang, ve Jenks sürdürülebilir mimarlıkta estetiğin, gelecekteki estetiğin yeni paradigmasını oluşturacağını belirtmiştir (Tablo 1).

\section{Örnekler üzerinden sürdürülebilir mimarlık estetik ilişkisi;}

Ele alınan örneklerde binanın hem iç mekanında hem de binanın dış yüzünü oluşturan cephesinde, çatısında ve kütlesinde sürdürülebilir mimarlığa yönelik tasarım yaklaşımlarına rastlamak mümkündür. Çalışmada özellikle yapının dış yüzeyine yansımış çatı, cephe ve kütle bölümleri ele alınmıştır. Resenburg Evi, Geleceğin Avustralya Konutu, Beyeler Foundation Müzesi, Bed Zed Toplu Konutu, Sonnenschiff Toplu Konutu, Green Roof Sanat Okulu, California Bilim Akademisi ve Civic Center Park Binası 'çatı' bölümü ele alınan yapılardır (Tablo 2). IBM Kulesi, Commerzbank Binası, Kanak Kültür Merkezi, Swiss Re Merkezi, Sapphire Rezidans Binası, Biotic Arch Kulesi, The Gate Rezidans, Biosphere Serası ve Farmscrapers Karma Kullanım Binası 'form' olarak ele alınan yapılardır (Tablo 3). British Pavyonu, Mont Cenis Training Merkezi, Cycle Bowl Pavyonu, Acros Fukuoka Binası, DIFC Lighthouse Kulesi, Cor Binası, Bahreyn Dünya Ticaret Merkezi, Strata SE1 Rezidansı, Güneş Odalı Apartman Kompleksi, Sierra Bonita Konutu, Pıxel Building Ofis Binası, MultiHued Kuggen Ofis Binası, Endessa Pavyonu, The Al Bahr Kuleleri ve Yanget Evi 'cephe' bölümü ele alınan yapılardır (Tablo 4). Sürdürülebilirlik açısından yapılan 
tasarımın bina bütünündeki etkisi, kullanılan malzeme çeşitliliği varsa aynı malzemenin değişiminin neler olduğu incelendiğinde;

- Resenburg Evi'nin eğimli çatısında çift cam kullanılarak yapının enerji korunumu desteklenmiştir. Geleceğin Avustralya Konutu'nun çatısına yerleştirilen rüzgar türbinleri ile rüzgar enerjisinden aktif olarak yararlanılmıştır. Beyeler Foundation Müzesi'nin çatısında eğimli opak cam güneşlik, açılabilir panjurlar, cam tavan ve delikli metal kullanılarak güneş ışınımları kontrol altına alınmıştır. Bed Zed Toplu Konutu'nun eğimli çatısında kullanılan renkli rüzgar gülleri ve fotovoltaik panaller ile teknik ve mekanik açıdan enerjinin etkin kullanımı sağlanmıştır. Sonnenschiff Toplu Konutu'nun eğimli çatısında fotovoltaik panallerle enerjinin etkin kullanımı sağlanmıştır.Green Roof Sanat Okulu'nun amorf yeşil çatısı, iç mekan ile dış mekan arasında tampon görevi görerek yapının enerji korunumu desteklenmiştir. California Bilim Akademisi'nin düz çatısında oluşturulan saydam tümsekler iç mekanda güneş enerjisinin toplanmasını desteklemiş, yeşil çatı kullanımı ile sürdürülebilirliğe katkı sağlamıştır. Cıvıc Center Park Binası'nın çatısında ise kullanılan fotovoltaik panallerle güneş enerjisinden mekanik yoldan yararlanılmıştır (Tablo 2).

Tablo 2. 'Çatı' bölümü ele alınan örnekler

\begin{tabular}{|l|l|l|l|l|}
\hline & Resim 3.Beyeler Foundation Müzesi, \\
Isviçe, 1997|
\end{tabular}

- IBM Kulesi bina bütününde binanın giriş katından başlamak üzere açılan boşluklar ile gök avlular oluşturulmuş, gök avlular düşeyde baca etkisi yaratarak hava sirkülasyonuna imkan tanımıştır. Commerzbank Binası'nın bazı katlarında oluşturulan atriumlar yardımıyla doğal havalandırma sağlanmıştır. Kanak Kültür Merkezi'nde bambu, çelik ve cam malzeme kullanılarak kavisli ve boşluklu yapı formu elde edilmiş ve bu boşluklar yardımıyla doğal havalandırma sağlanmıştır. Swiss Re Merkezi'nin aerodinamik formu, strüktür üzerindeki rüzgâr yükünü azaltmış, mekanik soğutma ve havalandırma sisteminde enerji tüketimini ve karbondioksit emilimini düşürmüştür. Sapphire Rezidans Binası'nın çift kabuk cephe sistemi ile ısı kazanımı sağlanmıştır. Biotic Arch Kulesi, dev dikey bahçeye sahip bina formu ile karbon emisyonunu en aza indirgenmeyi 
hedeflemiş, yapı formunun ortasındaki boşluğa yerleştirilen rüzgar türbini ile de mekanik yoldan enerji kazanımı sağlanmıştır. The Gate Rezidans da yeşil teraslarla ve terastan zemine uzanan yeşil oyuklarla karbon emisyonuna yardımcı olunmuş, çatıda kullanılan fotovoltaik panellerle de güneş enerjisinden yararlanılmıştır. Biosphere Serası, küre şeklindeki yapı formunda kullanılan saydam malzeme ile iç mekana enerji kazanımı sağlarken yeşil kullanımı ile mekanın içinde botanik alanlarda serinlemeye yardımcı gölge alanlar oluşturulmuştur. Farmscrapers Karma Kullanım Binası'nın yüzeyinde bulunan fotovoltaik paneller ve çatısında bulunan rüzgar türbinleri yardımıyla enerjinin etkin kullanımı sağlanmıştır. Ayrıca yapıda sebze ve meyve bahçeleri olarak tasarlanan yeşil alanlar ile karbon emisyonu sağlanmıştır (Tablo 3).

Tablo 3. 'Form' olarak ele alınan örnekler

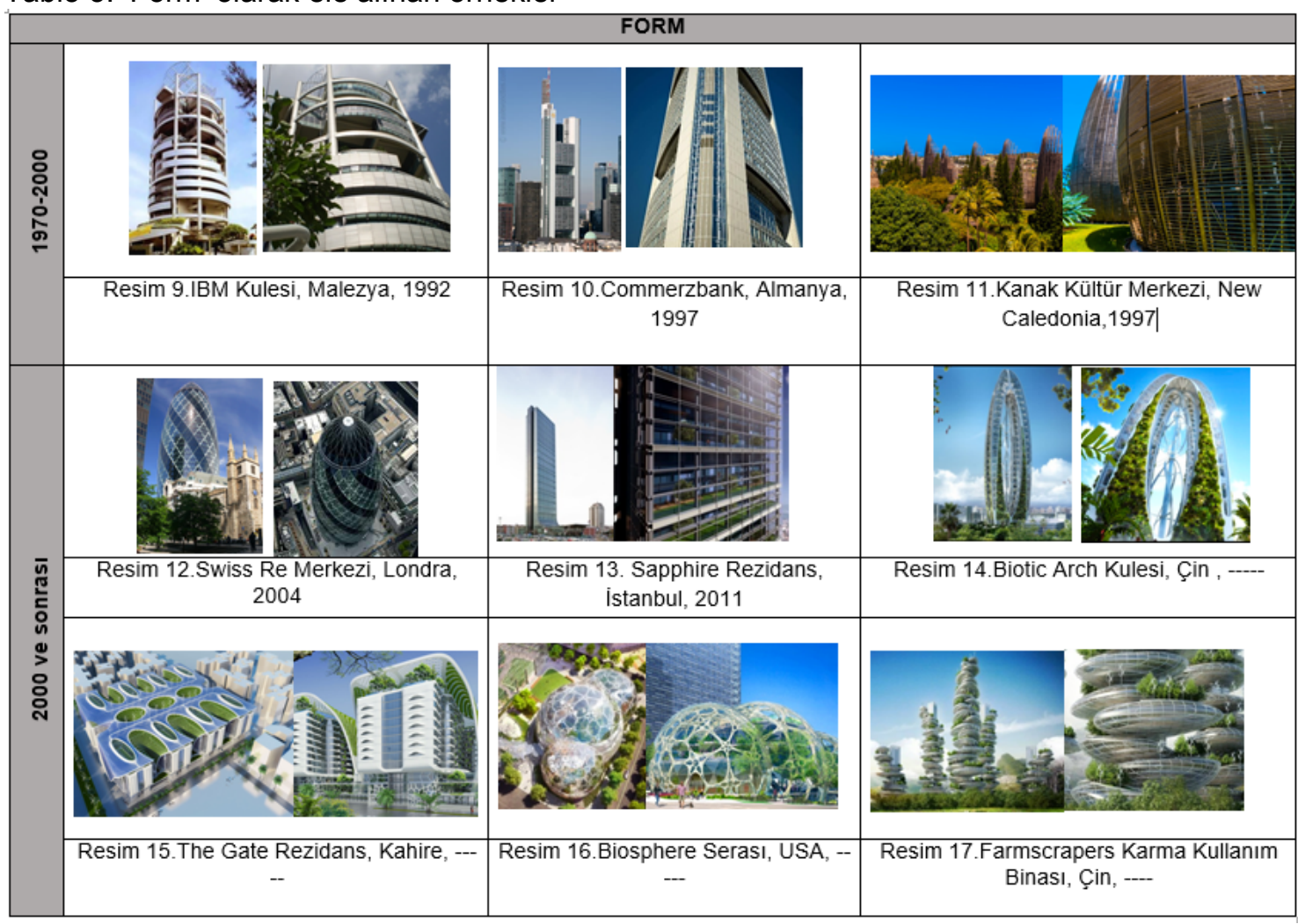

- British Pavyonu'nun cephesinde güneşin ısıtıcı etkisinden korunmak için pavyonun cephesi bir yüzey ile katmanlaştırılmış, kinetik su duvarı ile iç mekana ve çevreye pasif bir soğutma sağlanmıştır. Mont Cenis Training Merkezi ve Cycle Bowl Pavyonu'nun cephesindeki fotovoltaik paneller ile güneş enerjisinden mekanik yoldan enerji elde edilmiştir. Acros Fukuoka Binası'nın cephesindeki 'düşey yeşil duvarlar' kentsel ısı adası etkisini azaltmaya yardımcı olmuş, hava kalitesinin ve enerji verimliliğinin iyileştirilmesine destek olmuştur. DIFC Lighthouse Kulesi ve Cor Binası'nın cephe yüzeyindeki, Bahreyn Dünya Ticaret Merkezi'nin iki blok arasındaki ve Strata SE1 Rezidansı'nın cephe yüzeyindeki rüzgar türbinleri ile rüzgar enerjisinden mekanik yoldan enerji sağlanmıştır. Güneş Odalı Apartman Kompleksi'nin cephesinde kullanılan çift katmanlı kabuk sistemi ve güneş kırıcılar ile güneş ısısı kontrol altına alınmıştır. Sierra Bonita Konutu'nun cephesindeki güneş kırıcıları ile güneş ışınımından korunulmuş, fotovoltaik panellerle güneş enerjisinden yararlanılmıştır. Pıxel Building Ofis Binası'nın cephesinde kontrol edilebilen renkli gölgeleme 
elemanları/güneş kırıcılar ile güneşten korunulmuştur. Multi-Hued Kuggen Ofis Binası'nın cephesindeki koyu kırmızı renkte olan hareketli fotovoltaik renk perdesi ile hem iç mekana gölge sağlanmış hem de güneş enerjisinden yararlanılmıştır. Endessa Pavyonu'nun cephesinde fotovoltaik panellerle güneş enerjisinden yararlanırken güneş tuğlalarıyla güneşten koruma, izolasyon, havalandırma ve aydınlanma sağlanmıştır. The Al Bahr Kuleleri'nin cephesinde güneş ışınımlarına göre kendini sensörlerle ayarlayan petek bir sistem ile enerji korunumu sağlanmıştır. Yanget Evi cephesinde ise perde görevi gören renkli panellerin oluşturduğu ikinci bir katman ile güneşten korunulmuştur (Tablo 4).

Tablo 4. 'Cephe' bölümü ele alınan örnekler

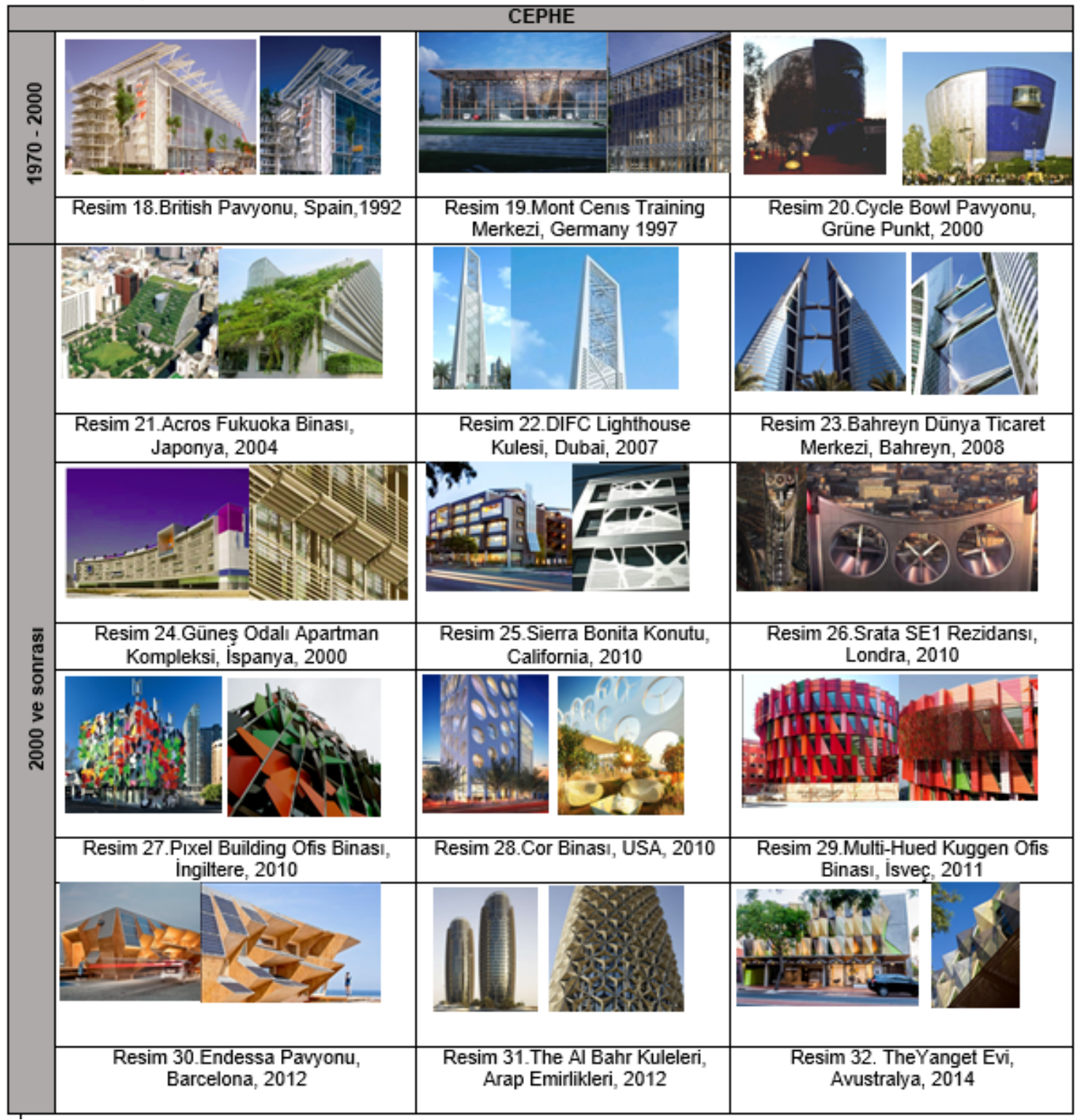

Özetle Sürdürülebilirlik açısından çatı bölümünde ele alınan örnekler incelendiğinde; sürdürülebilirlik özellikle mekanik yoldan fotovoltaik paneller ve rüzgar türbinleri ile sağlanmıştır. Pasif ısıtma ve soğutma olarak ise çift cam kullanımından ve çatılara dinamiklik katan güneş ışınlarını kontrol eden güneş kırıcılardan destek alınmıştır. Ayrıca çatılarda yeşil kullanım ile hem iç mekan ve dış mekan arasında tampon bölge oluşturulmuş hem de karbon emilimi sağlanmıştır. 
Sürdürülebilirlik açısından yapının bütünü ele alınan örnekler incelendiğinde; sürdürülebilirlik özellikle mekanik yoldan fotovoltaik paneller ve rüzgar türbinleri ile sağlanmıştır. Binada yer yer katlar arasında açılan avlular ile doğal havalandırma sağlanmıştır. Çift kabuk sistem ve saydam malzeme kullanımı ile de güneşten pasif olarak yararlanılmış, oluşturulan yeşil alanlar ile karbon emisyonuna destek olunmuştur. Sürdürülebilirlik açısından cephe bölümü ele alınan örnekler incelendiğinde; sürdürülebilirlik özellikle mekanik olarak yine fotovoltaik paneller ve rüzgar türbinleri ile sağlanmıştır. Bu teknik elemanlar bazı örneklerde cephe kompozisyonunun parçası olarak bazı örneklerde ise strüktür içine gizlenerek kullanılmıştır. Ayrıca tasarlanan özel gölgeleme elemanları/güneş kırıcılar ile ikinci bir katman oluşturulmuş ve güneş ışınları kontrol altına alınmıştır.

\section{Anket sonuçlarına göre sürdürülebilir mimarlık-estetik ilişkisi;}

Sürdürülebilir mimarlık yaklaşımının yapının özellikle dış yüzeyine yansıdığı örneklerin ele alındığı çalışmada, ele alınan tüm örneklerin mimarlık bölümü son sınıfa devam eden 100 öğrenciye 7'li ölçek kullanılarak estetik açıdan değerlendirildiğinde; Green Roof Sanat Okulu binası, 2006 (5,73) ile Acros Fukuoka Binası, 2004 (5,09) estetik değeri en yüksek sürdürülebilir yapı örnekleri olmuştur. Bed zed Toplu Konutu, 2000 $(2,2)$, Geleceğin Avustralya Konutu, $1992(2,79)$ ve Sonnenchift Toplu Konutu, 2004 $(2,94)$ ile estetik değeri en az bulunan örnekler olmuştur (Şekil 1).

Estetik değeri en fazla bulunan her iki yapıda da sürdürülebilirliği sağlayan 'yeşil' öğe kullanılmıştır. Green Roof Sanat Okulu'nun (Resim 6) çatısında yeşil kullanılırken Acros Fukuoka Binası'nın (Resim 21) cephesinde yeşil kullanılmıştır. Geleceğin Avustralya Konutu (Resim 2) örneğinin, çatısında bulunan rüzgar türbini ile sürdürülebilirliğin teknik/mekanik uygulamasını taşıdığı görülmüştür. Belirli bir hava akımının bulunduğu anda hareket eden türbinler rüzgarın kinetik enerjisini mekanik enerjiye çevirerek jeneratöre aktarmıştır. Bed zed Toplu Konut (Resim 4) uygulamasının sürdürülebilirlik durumu incelendiğinde binanın çatısında bulunan uygulamalar göze çarpmaktadır. Binanın gereken ısıtma ihtiyacını sağlamak üzere yapının son katında güneş odaları düzenlenmiştir. Sonnenschiff Toplu Konutu (Resim 5) örneği ise sürdürülebilirliği fotovoltaik panellerle sağlamıştır. Güneşten gelen fotonları elektrik enerjisine çeviren paneller, konutların çatı yüzeylerini kaplayarak güneş enerjisinden maksimum derecede yararlanmaya çalışmıştır (Tablo 5).

Tablo 5. Anket sonuçlarına göre estetik değeri en yüksek ve en az bulunan yapılar

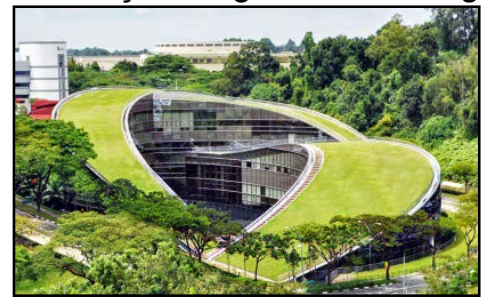

Resim 6. Green Roof Sanat Okulu

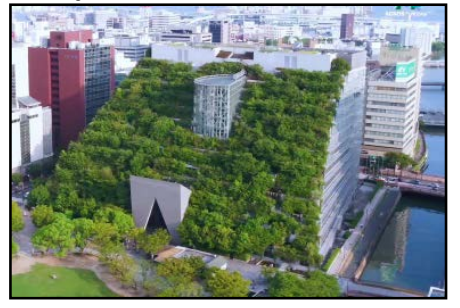

Resim 21. Acros Fukuoka Binası

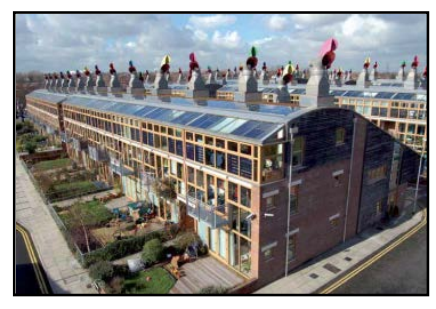

Resim 4.Bed zed Toplu Konutu

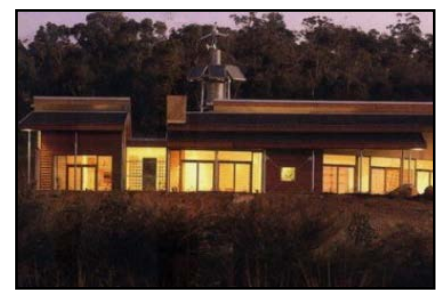

Resim 2.Geleceğin Avustralya Konutu

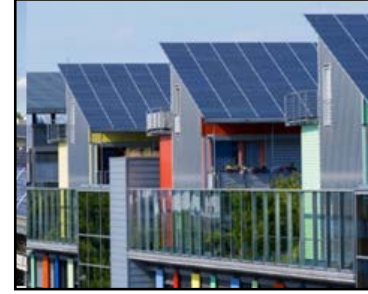

Resim 5.Sonnenschiff Toplu Konutu 


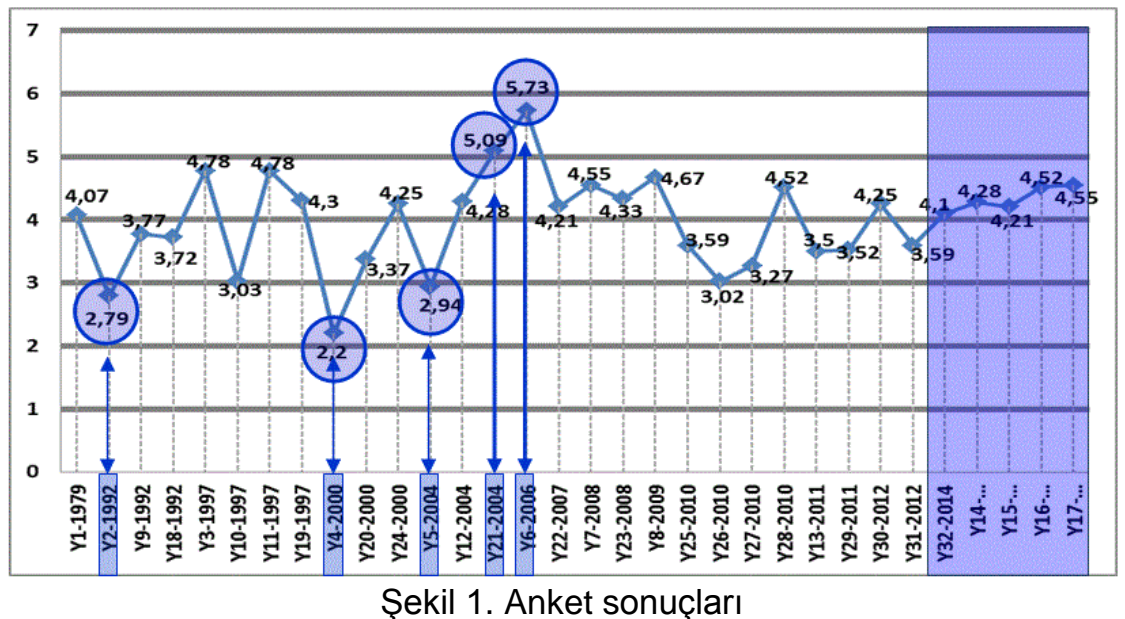

Genel bir değerlendirme yapıldığında; 1979'dan günümüze sürdürülebilir binaların estetik açıdan değişkenlik gösterdiği görülmüştür. Fakat 2014 yılı sonrasındaki örneklerde, estetik kalite açısından belirgin bir artış olmuştur. Bu artışın henüz uygulanmamış projeler olduğu dikkat çeken bir noktadır. Bu projelerin uygulanma durumunda estetik kalite değerinin değişebileceği de intimal dahilidir. Fakat söz konusu örneklerde estetik kaliteyi öne çıkaran öğenin binalarda özellikle sürdürülebilirliği sağlayan "yeşil kullanımı" olduğu dikkat çekicidir.

\section{SONUÇLAR}

Mimarlara ve kuramcılara göre sürdürülebilirlik- mimarlık ilişkisi değişkenlik göstermektedir. Yapılı çevre için sürdürülebilir mimarlığın estetik olabileceği ve olamayacağı, sürdürülebilir mimarinin gelişebilmesi için estetik yönünün bulunması gerektiği, bunun aksine sürdürülebilir mimarlıkta estetiğin aranmaması gerektiği, sürdürülebilir binaların estetiğinin geleceğin mimari akımını oluşturacağı üzerine farklı görüşler bulunmaktadır. Tüm bu görüşlerin yanında incelenen örneklerde gelişen teknoloji ile birlikte özellikle sürdürülebilirliği sağlayan teknik malzeme ve donanımın biçimsel olarak gelişme gösterdiği dikkat çekmektedir. Bazı örneklerde güneş kırıcılar, fotovoltaik paneller, rüzgar türbinleri gibi teknik donanımlar, özellikle çift cephe kullanımlarında çatı, cephe ve form fark etmeksizin tasarımın özellikle bir parçası olarak bina bütününde tasarlandığı görülmektedir. Ayrıca yeşil kullanımının ilk örneklerde kısıtlı kullanımı söz konusu iken yeni projelerde yapı bütününde kullanımı dikkat çekmektedir. 2000'li yıllardan günümüze sürdürülebilir mimarlıkta hala estetikten uzak malzemelerin ve teknoloji odaklı uygulamaların kullanılıyor olması estetik arayışın değişmekte olduğunu mimarlar tarafından da sürdürülebilir mimarlık ile estetik ilişkisinin net bir biçimde kurulmadığı veya kurulmaya çalışılmadığını göstermektedir. Fakat ister bu ilişki kurulmaya çalışılsın isterse çalışımasın anket sonuçlarına göre sürdürülebilirlik açısından yapılan yeşil kullanımların daha estetik bulunduğu görülmektedir.

Sonuç olarak doğal çevreyi koruyan ve devamlıı̆ını sağlayarak gelecek nesillerinde kullanıma imkân tanıyan sürdürülebilir mimarlık yapıları hem doğal çevre hem de yapılı çevre açısından önemli yapılardır. Hatta günümüzde hızı tüketilen kaynaklar açısından üzerinde durulan önemli tasarım problemlerinden birisidir. Hangi amaçla yapılıyor olursa olsun yapılı ve doğal çevrede yerini alan bu yapılar bu bütün içerisinde değerlendirilmektedir. Tüm bu farklı yaklaşımlara rağmen sayıları artan, güçlü ve etkili yüzler oluşturan sürdürülebilir yapılar, sürdürülebilir mimari için düşünülen mekanik bir yapı türü olmanın aksine teknoloji olanaklarıyla birlikte çeşitli yaratıcılık ve özgünlükleriyle yapılı çevrede yerini almaktadır. 


\section{KAYNAKLAR}

Baırd, George, Environmental Controls:Bridging Architectural Expression and Performance, Building Research \& Information, 2002, 30(1), pp.73-77.

Bauer, Micheal, Mösle, Peter, ve Schwarz, Micheal, Green Building, Springer Heidelberg Dordrecht, Berlin Heidelberg ,Springer-Verlag, 2007, pp.25.

Berleant, Arnold, Some Questions for Ecological Aesthetics, Environmental Philosophy, Spring, 2016, pp.123-135.

Christiaens, Hannelore, Three Renovation Proposals For An Environmental Educatıon Centre Located In Brıdgend Farmhouse, Edınburgh. Master Of Thesıs, The University of Edinburgh, 2013, pp.8.

Finocchiaro, Luca ve Hestnes, Anne Grete, Symbiosis and Mimesis in the Built Environment, ed. Lee, S., Aesthetics of Sustainable Architecture. Rotterdam: 010 Publishers, 2011, pp. $259-271$.

Frampton, Kenneth, Urbanization and İts Discontents: Mega for Mand Sustainability. ed. S. Lee, Aesthetics of Sustainable Architecture, Rotterdam: 010 Publishers, 2011, pp. 97-108.

Ghani, Fatima, Issues in Sustainable Architecture and Possible Solutions, International Journal of Civil \& Environmental Engineering, IJCEE-IJENS, 2012, Vol: 12 No: 01, pp.21-24.

Jauslın, Daniel, Landscape Aesthetics for Sustainable Architecture, ed. S, Lee, Aesthetics of Sustainable Architecture, Rotterdam: 010 Publishers, 2011, pp. 109-119.

Hosey, Lance, The Shape of Green, Washington: Island Press, 2012, pp. 2,3.

Jeffery, Jack, Governance for a Sustainable Future, Royal Institute of Public Health, London, 2006, pp.11.

Keskin, Kader, Enerji Etkin Mimarlıkta Pasif Sistem Parametrelerine Yönelik Bir Model Önerisi/ Ilıman Nemli Iklim Bölgesi Örneği, Yüksek Lisans Tezi, , Karadeniz Teknik Ünivesitesi, Mimarlık Fakültesi, Trabzon, 2014, ss.8

Kim, Jon Jin ve Rigdon, Brenda, Introduction to Sustainable Design, The University of Michigan, National Pollution Prevention Center for Higher Education, 1998, pp.7,8.

Kuban, Doğan, Mimarlık Kavramları, Yem Yayınevi, İstanbul, ss.56.

Kupatadze, La, Ethics vs. Aesthetics in Sustainable Architecture, WIT Transactions on Ecology on The Built Environment, 2014, vol 142, pp.553-562.

Lee, Sang, Aesthetıcs of Sustainable Architecture. 010 Publishers, Rotterdam, 2011, pp.29.

Lee Sang ve Holzheu Stefanie, Building Envelope as Surface. ed. S. Lee, Aesthetics of Sustainable Architecture. Rotterdam: 010 Publishers, 2011, pp. 120-133. 
Rostvik, Harad, The Vernacular, the Iconic and the Fake. ed.S. Lee, Aesthetics of Sustainable Architecture. Rotterdam: 010 Publishers, 2011, pp. 168-178.

Sendi, Mona, The Effect of Technology to Integrate Aesthetic Desire of Contemporary Architecture with Environmental Principles in Façade Design, International Scientific Journal Architecture and Engineering, 2014, Vol 2, Issue 1, pp.2

Rosenbaum, Marc, Green Building on Campus, ASHRAE Journal. Atlanta, GA. 2002, vol. 44, pp.41-44.

Sev, Ayşin, Sürdürülebilir Mimarlık, İstanbul, YEM Yayınları, Güzel Sanatlar Matbaası, 2009, pp.31.

Udomiaye, Emmanuel, Okon, lok, Uzodimma, Odom Christopher ve Patrick, Ntaji, EcoFriendly Buildins: The Architect's Perspectives, International Journal of Civil Engineering, Construction and Estate Management, 2018, vol.6, No.2, pp.14-26.

Vitruvius, Mimarlık Üzerine On Kitap, çev. Suna Güven, İstanbul Şevki Vanlı Mimarlık Vakfı Yayınevi, 2005, pp.12.

Yeang, Ken, Ecodesign: A manual for Ecological Design. London : Wiley - Academy, 2006, pp.23.

Yücel, Çiğdem, Ekolojik Yapı Estetik Ilişskisinin Deneysel Olarak Incelenmesi, Doktora Tezi, Gazi Üniversitesi, Mimarlık Fakültesi, Ankara, 2011, pp.44.

Wahba, Sherine Mohy El Dine, Friendly and Beautiful: Environmental Aesthetics in Twenty-First-Century Architecture, Nexus Network, 2010, Journal 12, pp. 459-469.

Wheeler, Andrea, Outsider Ethics and Marginalized Aesthetics: The Value of Contemporary Environmental Philosophies for Designing Sustainable Architecture, Architecture Conference Proceedings and Presentations, lowa State Unıversity, Plea, Edinburgh, 2017, pp.9.

Zhe Wang, Lia Zhou, ve Jing Shi, On the Beauty of Green Expo Architecture and Sustainable Development-Taking "China Pavilion" as an Example., Procedia Engineering, 2011, 21, pp.163- 167.

\section{İnternet Kaynakları}

https://www.treehugger.com/sustainable-product-design/why-is-so-much-greenarchitecture-so-ugly.html [Erişim tarihi 12 Mart 2019, 13:55]

https://issuu.com/benedictebrekke/docs/aesthetics and sustainable architec [Erişim tarihi 24 Mart 2019, 13:45]

https://docplayer.nl/19528613-21-05-28-08-2011-architecture-museum-la-logekluisstraat-86-1050-brussel.html [Erişim tarihi 24 Nisan 2019, 14:20]

\section{https://arch.design.umn.edu/directory/guzowskim/documents/AIACOTEsolar.pdf}

[Erişim tarihi 22 Nisan 2019, 15:35] 
Resim1.https://www.mydstudio.com/blog/sustainable-modernism-house-inregensburg.html [Erişim tarihi 24 Nisan 2019, 16:45]

Resim 2. https://inhabitat.com/monier-off-the-grid-house-by-ackert-architecture/ [Erişim tarihi 25 Nisan 2019, 17:20]

Resim3.http://rpf.ice.spill.net/project/84/beyeler-foundationmuseum/images/enlarged/1777/ [Erişim tarihi 2 Mayıs 2019, 14:55]

Resim4.http://www.yapi.com.tr/haberler/sifir-karbon-emisyonlu-bir-dunya-insaetmek 47650.html [Erişim tarihi 23 Nisan 2019, 09:45]

Resim 5. https://www.ice.org.uk/about-ice/near-you/uk/london/awards/london-civilengineering-awards [Erişim tarihi 20 Nisan 2019, 13:30]

Resim 6. https://tr.pinterest.com/pin/335518240971942106/?|p=true [Erişim tarihi 20 Nisan 2019, 11:25]

Resim 7. http://v3.arkitera.com/h21418-kaliforniya-bilim-akademisi-dunya-daki-enekolojik-muze-olmayi-amacliyor.html [Erişim tarihi 3 Mayıs 2019, 10:40]

Resim 8. http://www.moorerubleyudell.com/projects/santa-monica-civic-center-parkingstructure [Erişim tarihi 3 Mayıs 2019, 10:50]

Resim 9. https://archnet.org/sites/957/media contents/9622 [Erişim tarihi 3 Mayıs 2019, 11:15]

Resim 10. http://www.gothereguide.com/commerzbank+tower+frankfurt-place/ [Erişim tarihi 3 Mayıs 2019, 16:25]

Resim 11. https://www.alamy.com/tjibaou-cultural-center-by-architect-renzo-pianonoumea-grand-terre-image60636041.html [Erişim tarihi 5 Mayıs 2019, 15:55]

Resim 12. https://www.e-architect.co.uk/london/swiss-re-building [Erişim tarihi 5 Mayıs 2019, 13:35]

Resim 13. https://www.archdaily.com/141615/istanbul-sapphire-tabanlioglu-architects [Erişim tarihi 20 Nisan 2019, 14.50]

Resim 14. https://inhabitat.com/vincent-callebauts-zero-carbon-biotic-arch-is-a-gnarlyself-sufficient-skyscraperl [Erişim tarihi 20 Nisan 2019, 15:55]

Resim 15. https://interestingengineering.com/the-gate-residence-will-promoteenvironmental-sustainability [Erişim tarihi 20 Nisan 2019, 16:30]

Resim 16. https://tr.pinterest.com/pin/561190803540941460/ [Erişim tarihi 20 Nisan 2019, 15:40]

Resim 17. https://www.pinterest.co.uk/pin/291889619575812924/ [Erişim tarihi 21 Nisan 2019, 14:50]

Resim 18. https://grimshaw.global/projects/british-pavilion-expo/ [Erişim tarihi 21 Nisan 2019, 14:25] 
Resim 19. https://www.agefotostock.com/age/en/Stock-Images/education-academymont-cenis.html [Erişim tarihi 21 Nisan 2019, 14:15]

Resim 20. https://www.atelier-brueckner.com/de/projekte/cyclebowl [Erişim tarihi 24 Nisan 2019, 15:30]

Resim 21. https://www.kilsanblog.com/yesil-cevreci-ekolojik/merdivenlerle-parkadonusturulmus-carpici-bir-kamu-binasi-acros-fukuoka/ [Erişim tarihi 24 Nisan 2019, $11: 35]$

Resim 22. http://www.greentechno.com/leed-project-management-difc-lighthousedubai-uael [Erişim tarihi 24 Nisan 2019, 16:25]

Resim 23. https://www.enteresan.com/bahreyn-dunya-ticaret-merkezinin-devasaruzgar-turbinleri [Erişim tarihi 24 Nisan 2019, 11:15]

Resim 24. https://tr.pinterest.com/pin/170433167119484348/?|p=true [Erişim tarihi 25 Nisan 2019, 11:40]

Resim 25. https://www.huduser.gov/portal/casestudies/study 07062015 1.html [Erişim tarihi 25 Nisan 2019, 14:20]

Resim 26. https://asliceylan.wordpress.com/2010/03/16/ruzgar-gullugokdelen/\#respond [Erişim tarihi 24 Nisan 2019, 10:30]

Resim 27. https://inhabitat.com/pixel-building-australias-first-carbon-neutral-building-isnow-complete/ [Erişim tarihi 25 Nisan 2019, 11:10]

Resim 28. https://www.archdaily.com/87063/cor-oppenheim-architecture-design [Erişim tarihi 25 Nisan 2019, 13:25]

Resim 29. https://inhabitat.com/multi-hued-kuggen-building-the-cog-features-a-rotatingphotovoltaic-shade-screen/ [Erişim tarihi 25 Nisan 2019, 15:55]

Resim 30. https://www.archdaily.com/274900/endesa-pavilion-iaac [Erişim tarihi 2 Mayıs 2019, 13:30]

Resim 31. https://www.casadomo.com/2019/03/22/fachada-automatizada-torres-albahr-ayuda-reducir-incidencia-sol-interior-edificio [Erişim tarihi 2 Mayıs 2019, 12:50]

Resim 32. https://bookmarc.io/au/supplier/anodisers-wa/albums/12095/yanget-house [Erişim tarihi 2 Mayıs 2019, 11.25] 